\title{
ACESSIBILIDADE DE PESSOAS COM DEFICIÊNCIA EM UMA UNIDADE DE ALIMENTAÇÃO E NUTRIÇÃO NA CIDADE DE SÃO PAULO
}

\section{ACCESSIBILITY OF PEOPLE WITH DISABILITIES IN A FOOD SERVICE IN THE CITY OF SÃO PAULO}

\author{
Jhenevieve Cruvinel ${ }^{1}$ \\ Mônica Glória Neumann Spinelli² \\ Hellen Daniela Sousa Coelho ${ }^{3}$
}

Resumo: O principal objetivo das Unidades de Alimentação e Nutrição é o fornecimento de refeições seguras, nutricionalmente equilibradas, adequadas ao contexto sócio cultural a que está inserida. No que tange a estes princípios, é possível observar diversos estudos, metodologias e processos que visam garantir a qualidade da alimentação. No entanto, as UANs são pontos importantes de socialização: o alimentar se envolve também com questões emocionais de pertencimento a um grupo e a uma sociedade. O propósito deste artigo foi refletir sobre as variáveis que tangem a questão da acessibilidade em uma Unidade de Alimentação e Nutrição. Observacional e descritivo. Usou-se como ferramenta avaliativa a aplicação de checklist adaptado do roteiro de acessibilidade do Ministério Público e as normas da ABNT 9050 atualizada. As dificuldades e limitações enfrentadas por pessoas com deficiência são ampliadas em situações em que sua acessibilidade não é garantida, tornando a realização das tarefas cotidianas empecilho maior do que a característica de sua deficiência. As empresas devem pensar não somente na acessibilidade do seu colaborador ao trabalho, mas também ao momento da refeição. Faz-se necessária reflexão sobre o conceito de acessibilidade em seu contexto amplo, promovendo inclusão e destacando as UANs como ambientes que promovem inclusão e responsabilidade social.

Palavras-chave: Acessibilidade. Pessoas com deficiência. Nutrição. Serviço de Alimentação.

Abstract: The main purpose of the Food Services (FS) is the provision of safe and nutritionally balanced meals, respecting the cultural context to which it is inserted. Regarding these principles, it is possible to observe several studies, methodologies and processes that aim to guarantee food quality. Nevertheless, FS represent an important aspect of socialization: the nourishment process includes emotional aspects of belonging to a group and to the society. The purpose of this article is to reflect on the variables that concern the issue of accessibility in a Food Service. It is an observational and descriptive work, where the application of a checklist adapted from the accessibility roadmap of the Public Prosecutor's Office and the updated ABNT 9050 standards was used as an evaluative tool. The difficulties and limitations faced by people with disabilities are magnified in situations where their accessibility is not guaranteed, making the performance of daily tasks more difficult than the characteristic of their disability. Companies should think not only about their employee's accessibility

\footnotetext{
${ }^{1}$ Nutricionista graduada pela Universidade Paulista - UNIP, E-mail: ihenecruvinel@gmail.com.

2 Docente titular do Curso de Nutrição da Universidade Paulista UNIP, E-mail: monicaspi404@gmail.com.

3 Docente do curso de Nutrição da Universidade Paulista - UNIP, E-mail: hellen.coelho@docente.unip.br.
} 
to work, but also at the time of the meal. It is necessary to reflect on the concept of accessibility in its broad context, promoting inclusion and highlighting FS as environments that promote inclusion and social responsibility.. It is necessary to reflect on the concept of accessibility in its broad context, promoting inclusion and highlighting a FS as environments that promote inclusion and social responsibility.

Key words: Accessibility. People with disabilities. Nutrition. Food servisse.

Data de submissão: 14.08 .2020

Data de aprovação: 07.04.2021

Identificação e disponibilidade:

(https://revista.univap.br/index.php/revistaunivap/article/view/2541, http://dx.doi.org/10.18066/revistaunivap.v27i56.2541).

\section{INTRODUÇÃO}

As Unidades de Alimentação e Nutrição (UAN) têm como objetivo o fornecimento de refeições nutricionalmente equilibradas, seguras e adequadas à população atendida, visando a manutenção ou recuperação da saúde e também visando auxiliar no desenvolvimento de hábitos alimentares saudáveis e a educação alimentar e nutricional. A satisfação do cliente no que diz respeito aos serviços oferecidos, abrange além destas questões o ambiente físico, outro conceito amplo, que engloba diferentes fatores, como higiene do ambiente e equipamentos, atendimento aos comensais e a ambiência (TEIXEIRA et al., 2010).

Neste contexto, a ambientação é compreendida por diversos fatores, entre eles, a decoração, música no ambiente, atendimento dispendido ao cliente. A ambiência está vinculada também a outro conceito, que é a atmosfera, ou seja, refere-se ao estado de espírito transmitido pelo lugar e que pode influenciar os comensais e sua interação entre si e o ambiente. Todos os componentes do binômio ambientaçãoatmosfera podem ser os bens tangíveis, mobília, decoração interior, os bens intangíveis, a refeição festiva, o atendimento e estes fatores interferem na experiência de sociabilidade, na criação e fortalecimento de laços entre as pessoas (ABREU; SPINELLI; PINTO, 2019).

A preocupação com a ambiência é um dos fatores principais no planejamento físico de uma UAN, considerada um conjunto complexo de elementos que dispõe as funções administrativas, operacionais e clientes, e define no geral a quantidade e o aproveitamento do serviço prestado, estando diretamente relacionada à qualidade do serviço prestado (SANT'ANA, 2012), tendo a construção de UANs, como base o planejamento físico adequado, importância fundamental para atender às expectativas e necessidades dos clientes finais (ABREU; SPINELLI; PINTO, 2019).

Além destas questões, deve-se pensar no planejamento e atividades da UAN no que se refere à inclusão de pessoas com deficiência, através da acessibilidade, para que os espaços desenhados não imponham obstáculos que impeçam o pleno gozo e exercício dos direitos da Pessoa com Deficiência, ou de qualquer outra pessoa. $O$ termo acessibilidade, historicamente, tem sua origem na década de quarenta para designar a condição de acesso das pessoas com deficiência vinculada ao surgimento dos serviços de reabilitação física e profissional. Inicialmente era descrita como condição de mobilidade e eliminação das barreiras arquitetônicas e urbanísticas, numa clara alusão às condições de acesso a edifícios e meios de transporte 
(TORRES; MAZZONI; ALVES, 2002; ARAÚJO; CÂNDIDO; LEITE, 2009; LAQUALE, 2017).

Em 2015, a Lei Brasileira de Inclusão da Pessoa com Deficiência (Estatuto da Pessoa com Deficiência) (Lei $N^{\circ} 13.146$, de 6 de julho de 2015), em seu Art. $3^{\circ}$, parágrafo IV, apresenta item que descreve também as barreiras atitudinais, que são descritas como, atitudes ou comportamentos que impeçam ou prejudiquem a participação social da pessoa com deficiência em igualdade de condições e oportunidades com as demais pessoas, demonstrando uma mudança que engloba o indivíduo em suas diferentes necessidades e aspectos.

No que tange às barreiras físicas e do ambiente dentro da UAN, cabe ao Nutricionista cooperar no planejamento físico-funcional das UANs, como determinado na Lei 8.234/91, que regulamenta a profissão e com a Resolução CFN $600 / 2018$, que define as áreas de atuação e atribuições do profissional, nas quais se pode ressaltar a participação na elaboração e implantação de projetos físicos da UAN e a supervisão da adequação das condições estruturais e dos equipamentos e materiais utilizados (BRASIL, 1991; CFN, 2018).

A inclusão social de pessoas com deficiência é um processo que requer ações estruturadas e planejadas capazes de criar um movimento que, de modo geral, não acontece naturalmente, sendo um passo importante para este processo a adaptação de determinados locais de trabalho para alocar essas pessoas. No entanto, para efetividade do processo de inclusão, a empresa deve eliminar as barreiras existentes no contexto de sua organização, sejam elas arquitetônicas, de comunicação, programáticas ou atitudinais. As barreiras atitudinais que dizem respeito ao comportamento humano frente à falta de acessibilidade nas demais barreiras, através de posturas que limitam as possibilidades de desenvolvimento e de relação social. A remoção dessas barreiras é que faz com que o acesso das pessoas com deficiência seja facilitado, assim como seu desenvolvimento pessoal, social, educacional e profissional (BAHIA; SCHOMMER, 2010; RIBEIRO, 2016).

A Declaração Universal dos Direitos das Pessoas Portadoras de Deficiência, aprovada em 1975 pela Organização das Nações Unidas (ONU) e a Convenção Internacional $n^{\circ} 159$ da Organização Internacional do Trabalho (OIT), de 1983, são marcos desse processo e influenciaram práticas em diversos países (RIBEIRO; CARNEIRO, 2009). A inclusão, requer planejamento prévio e um alinhamento que perpasse todos os processos de gestão, promovendo estratégias e estruturas em alinhamento com os objetivos da empresa, de maneira a alavancar o processo de maneira dinâmica e contínua, investindo na acessibilidade interna e no desenho do trabalho, na formação, dentre outros aspectos culturais dentro da empresa (CARDOSO; ARAÚJO, 2006; SIMONELLI; JACKSON FILHO, 2017).

Segundo dados do Instituto Brasileiro de Geografia e Estatística - IBGE divulgados em 2012, o Brasil tem 45,6 milhões de pessoas com deficiência e, dos 190 milhões de brasileiros, $23,9 \%$ da população possuem ao menos uma deficiência, seja esta visual, auditiva, motora ou mental em algum grau. Já com a nova avaliação dos dados em 2018, considerando apenas pessoas que possuem grande ou total dificuldade para enxergar, ouvir, caminhar ou subir degraus, além dos que declararam ter deficiência mental ou intelectual, são mais de 12,5 milhões de brasileiros com deficiência, o que corresponde a $6,7 \%$ da população. Necessário se faz a percepção de que essas pessoas também fazem parte do contingente de consumidores, frequentam bares, restaurantes, e muitas vezes não encontram condições adequadas, ou seja, não vivem em uma sociedade adaptada, ainda que este seja um direito previsto pela lei brasileira (IBGE, 2013; 2015; 2019). 
O direito à acessibilidade de pessoas com deficiência se fundamenta nos direitos humanos e de cidadania, sendo regulamentado, no Brasil, pela Norma Brasileira 9050 da Associação Brasileira de Normas Técnicas (ABNT) de 2004, atualizada em 2015. Nesta, são fixados os critérios e parâmetros técnicos para elaboração de projetos, construções, instalações e adaptações de edifícios, mobiliário, espaços e equipamentos urbanos as condições de acessibilidade (ABNT, 2015).

Além das barreiras físicas e estruturais é necessário que se amplie o olhar, que as UANs, quanto prestadoras de um serviço, alinhem-se com a legislação brasileira vigente, que define que, toda pessoa, incluindo aquelas que apresentam deficiências, tem direito ao livre acesso, portanto, devem ser percebidas com igualdade, implicando assim no reconhecimento e atendimento de suas necessidades especificas, o que é imprescindível para garantia de sua dignidade (ANDRADE; PACHECO; FARIAS, 2007; PESCHUTI; LIMA, 2017).

A integração social ocorre por meio do estabelecimento de relações de reconhecimento, através das quais, as pessoas são confirmadas como sujeitos em diferentes aspectos de suas personalidades, e partindo deste reconhecimento se tornam parte de uma sociedade. Conceituações estigmatizadas que trazem em seu bojo as representações da pessoa com deficiência como alguém a quem falta algo gerando conotação incapacitante promovem desvalorização e prejuízo nas relações. A qualidade moral, social desta integração, pode ser aperfeiçoada, aumentando assim as partes reconhecidas e vistas da personalidade e necessidade dos indivíduos, mediante então a individualização da inclusão (HONNETH, 2006; PESCHUTI, LIMA, 2017).

A necessidade do homem está além da busca por alimentos que the tragam satisfação (NOBRE, 2009) e suas necessidades e desejos se potencializam conforme a evolução da sociedade moderna. Neste sentido, a busca pelas empresas para manter níveis competitivos no mercado determina a sua necessidade de extrair a máxima satisfação de seus clientes (VIANA et al., 2014).

Trazer os grupos minoritários para dentro de ambientes que estes não costumavam ocupar, tornou-se uma estratégia competitiva dentro das empresas e colaborou para a preocupação com a diversidade e inclusão social. Uma empresa inclusiva é a que mostra transformações nos ambientes físicos, nos procedimentos técnicos, nos meios de comunicação, assim como na mentalidade de todas as pessoas, inclusive da própria pessoa com deficiência (BAHIA, 2006; SANTOS; SANTANA; ARRUDA, 2018).

O presente artigo nasceu da reflexão sobre o atendimento de pessoas com deficiência dentro da Unidade de Alimentação e Nutrição e o processo de inclusão em sentido amplo, de maneira a promover a inclusão de sujeitos no circuito de membros plenos da sociedade.

Assim, o objetivo deste artigo foi avaliar variáveis que tangem a questão da acessibilidade em uma Unidade de Alimentação e Nutrição.

\section{METODOLOGIA}

Foi realizado estudo observacional e descritivo, no primeiro semestre de 2019, em uma Unidade de Alimentação e Nutrição localizada no município de São Paulo, em um condomínio empresarial de alto padrão, cujo restaurante, com gestão terceirizada, alto padrão de cardápios e serviços, oferece em média 850 refeições no horário do almoço, o que é considerado como unidade de médio porte por Sant 'Ana (2012). Em média, diariamente, fazem a refeição almoço 48 portadores de deficiência, 
sendo aproximadamente $50 \%$ de cada sexo, conforme política de equidade das empresas do condomínio.

É através da observação atenta aos detalhes que o pesquisador inserido dentro do cenário participa de forma que possa compreender a complexidade dos ambientes psicossociais, ao mesmo tempo em que lhe permite uma interlocução mais competente, resultando numa análise dos comportamentos espontâneos e à percepção de atitudes não verbais (ZANELLI, 2002).

Como norteador para as observações e ferramenta avaliativa para verificar se a unidade está adequada às normas e diretrizes previstas na legislação, referentes a acessibilidade de pessoas com deficiência, foi realizada a aplicação de check-list adaptado do roteiro de acessibilidade do Ministério Público em conjunto as normas da ABNT 9050 atualizada em 2015 (ABNT, 2015).

Foi realizado um diagnóstico inicial utilizando como base a ABNT NBR9050 e os seguintes pontos foram destacados para a pesquisa: 1: analisar quais as barreiras físicas que limitavam ou impediam as Pessoas com Deficiência (PCD); coleta de dados espaciais, de fluxo e de demanda. 2: avaliar o grau de independência funcional das pessoas com deficiências; o quanto podem realizar de maneira autônoma suas refeições; 3: se há desconforto social; sensação referente ao atendimento e ambiente; 4: a percepção e preparo dos funcionários na realização do atendimento das pessoas com deficiência.

As opções de respostas para o preenchimento do check-list foram: "Conforme" (C) - quando o restaurante atendeu ao item observado, "Não Conforme" (NC) quando o restaurante apresentou Não-conformidade para o item observado e "Não Aplicável" (NA) - quando o item foi considerado não pertinente ao local pesquisado. Os dados foram apresentados em forma de quadros para melhor observação e os resultados discutidos com base nas normas citadas acima e estudos congruentes ao tema.

O presente estudo faz parte de um projeto maior intitulado "Gestão da Qualidade em Serviços de Alimentação" com aprovação do Comitê de Ética em Pesquisa da Universidade Paulista - UNIP - CAAE:43235615.1.0000.5512.

\section{RESULTADOS E DISCUSSÃO}

As pessoas com deficiência (PCD) ou mobilidade reduzida podem ter dificuldade de locomover-se e geralmente fazem uso de equipamentos que as ajudam, como a cadeira de rodas, o andador, a bengala, a muleta, o carro adaptado. Torna-se imprescindível que haja o preparo dos espaços externos e internos da UAN para o atendimento inclusivo (SEBRAE, 2015).

Neste contexto, embora o escopo deste trabalho tenha sido a observação do ambiente inclusivo para os funcionários fazerem suas refeições, não é possível esta análise sem contemplar o acesso externo. Assim, os primeiros itens observados, se referem à estrutura e às barreiras físicas impeditivas desta inclusão. Foi observada uma cultura inclusiva bem estabelecida, dinâmica e os espaços externos pensados e planejados para uma inclusão social na empresa voltados aos diferentes tipos de deficiência. Quanto aos tipos de necessidades especiais observados, foram mais prevalentes as deficiências físicas, paraplegia, monoplegia, monoparesia e amputação.

As instalações do restaurante se situam isoladas das demais edificações, no centro do condomínio, estacionamento com vagas preferenciais, calçadas com largura superior a 1,20m, rampas de acesso e faixa de pedestres elevadas ao nível da 
calçada, sinalização e piso direcional de acordo com as normas (ABNT, 2015), conforme se observa no Quadro 1, na adequação das conformidades verifica-se que dos nove itens avaliados oito encontravam-se de acordo, garantindo $88,9 \%$ das conformidades nesse espaço.

Quadro 1 - Avaliação das conformidades nas áreas externas (AE) e internas (AI), segundo barreiras físicas limitantes ou impeditivas de mobilidade e acesso. São Paulo 2019.

\begin{tabular}{|c|c|c|c|}
\hline Áreas & *Itens Analisados & Conforme & Não conforme \\
\hline $\mathrm{AE}$ & $\begin{array}{l}\text { Possui faixa livre para pedestre? (Ideal 1,50m, admissível } \\
1,20 \mathrm{~m} \text { ) }\end{array}$ & $\mathrm{X}$ & \\
\hline $\mathrm{AE}$ & $\begin{array}{l}\text { Nível da calçada respeita o meio-fio instalado, sem } \\
\text { sobreposição de piso ou descaracterização deste nível? }\end{array}$ & $\mathrm{X}$ & \\
\hline $\mathrm{AE}$ & $\begin{array}{l}\text { A calçada é livre de obstáculos no piso, que comprometam } \\
\text { a rota acessível? }\end{array}$ & $\mathrm{X}$ & \\
\hline $\mathrm{AE}$ & $\begin{array}{l}\text { A calçada possui piso direcional tátil, instalado } \\
\text { corretamente (largura mínima } 0,25 \mathrm{~cm}) ?\end{array}$ & $\mathrm{X}$ & \\
\hline $\mathrm{AE}$ & $\begin{array}{l}\text { Há vagas preferenciais em quantidade adequada e } \\
\text { próximas a porta de entrada? }\end{array}$ & $\mathrm{X}$ & \\
\hline $\mathrm{AE}$ & $\begin{array}{l}\text { A rampa atende a largura mínima de } 1,50 \mathrm{~m} \text {, sendo } \\
\text { admissível } 1,20 \mathrm{~m} \text { e atende a inclinação máxima de } \\
8,33 \% \text { ? }\end{array}$ & $\mathrm{X}$ & \\
\hline $\mathrm{AE}$ & $\begin{array}{l}\text { Tem corrimão intermediário para as rampas, com largura } \\
\text { a partir de } 2,40 \mathrm{~m} \text { ? }\end{array}$ & & $X$ \\
\hline \multirow[t]{2}{*}{$\mathrm{AE}$} & $\begin{array}{l}\text { As portas atendem a largura livre mínima de } 0,80 \mathrm{~cm} \text { e } \\
\text { altura de } 2,10 \mathrm{~m} \text { ? }\end{array}$ & $X$ & \\
\hline & $\begin{array}{l}\text { As portas acionadas por sensores de presença são ajustad } \\
\text { detectar pessoas de baixa estatura, crianças e usuários } \\
\text { de cadeiras de rodas? }\end{array}$ & $X$ & \\
\hline $\mathrm{Al}$ & $\begin{array}{l}\text { Balcão de atendimento possui altura máxima de } 0,90 \mathrm{~cm} \text {, } \\
\text { com altura livre de } 0,73 \mathrm{~cm} \text { do piso e } 0,90 \mathrm{~cm} \text { de extensão } \\
\text { mínima? }\end{array}$ & & $\mathrm{X}$ \\
\hline $\mathrm{Al}$ & $\begin{array}{l}\text { Permite que o usuário de cadeira de rodas avance sob o } \\
\text { balcão até } 0,30 \mathrm{~cm} \text { no mínimo? }\end{array}$ & & $\mathrm{X}$ \\
\hline $\mathrm{Al}$ & $\begin{array}{l}\text { Balcões de auto serviço: as bandejas, talheres, pratos, } \\
\text { estão dispostos dentro da faixa de alcance manual } \\
(0,50 \mathrm{~cm} \text { de profundidade e } 1,20 \mathrm{~m} \text { de altura }) \text { ? }\end{array}$ & $\mathrm{X}$ & \\
\hline $\mathrm{Al}$ & $\begin{array}{l}\text { Balcões de auto serviço: copos, bebidas, temperos e } \\
\text { alimentos estão dispostos ao alcance manual }(0,50 \mathrm{~cm} \text { de } \\
\text { profundidade e } 1,20 \mathrm{~m} \text { de altura)? }\end{array}$ & & $\mathrm{X}$ \\
\hline $\mathrm{Al}$ & Altura das máquinas de café garante acessibilidade? & & X \\
\hline $\mathrm{Al}$ & Piso interno utilizado é adequado e antiderrapante? & & $\mathrm{X}$ \\
\hline $\mathrm{Al}$ & $\begin{array}{l}\text { Banheiro: dispõe de pelo menos um banheiro acessível, } \\
\text { por pavimento, com entrada independente dos sanitários } \\
\text { coletivos? }\end{array}$ & $\mathrm{X}$ & \\
\hline $\mathrm{Al}$ & $\begin{array}{l}\text { A dimensão mínima do banheiro (não inclui chuveiro) } \\
\text { atende a especificidade da norma técnica }(1,50 \mathrm{~m} \text { por } \\
1,70 \mathrm{~m}) ?\end{array}$ & $\mathrm{X}$ & \\
\hline $\mathrm{Al}$ & Banheiro: o sentido de abertura da porta é para fora? & $X$ & \\
\hline
\end{tabular}

* Foram considerados apenas os itens exigidos pela NBR 9050/2015 e legislação federal em vigor, remetendo-se consulta as leis estaduais e municipais, como complemento, além das recomendações contidas na norma técnica mencionada.

$\mathrm{AE}$ - área externa

$\mathrm{Al}$ - área interna

Fonte: Elaborado pelos autores. 
Quadro 2 - Avaliação dos fatores da área interna do restaurante que facilitam a independência funcional das pessoas com deficiências. São Paulo, 2019.

\begin{tabular}{|l|c|c|}
\hline *Itens Analisados: & Conforme & Não Conforme \\
\hline Há atendimento preferencial (balcões, filas)? & & $\mathrm{X}$ \\
\hline $\begin{array}{l}\text { Acessibilidade Funcional; Há interprete em LIBRAS, opção } \\
\text { de cardápio em Braille? }\end{array}$ & & $\mathrm{X}$ \\
\hline $\begin{array}{l}\text { Funcionários receberam treinamento específico, orientado } \\
\text { ao atendimento de PCD? }\end{array}$ & \\
\hline Há funcionário fixo para o atendimento de PCD? & $\mathrm{X}$ \\
\hline $\begin{array}{l}\text { A altura dos balcões permite que toda PCD possa se servir } \\
\text { de maneira autônoma? }\end{array}$ & \\
\hline $\begin{array}{l}\text { Há uma faixa de circulação de 0,90m entre as mesas e } \\
\text { área de manobra para acesso às mesmas? }\end{array}$ & $\mathrm{X}$ \\
\hline $\begin{array}{l}\text { A mobília permite que o usuário de cadeira de rodas } \\
\text { avance sob a mesa, no mínimo, 0,50m? }\end{array}$ & $\mathrm{X}$ & \\
\hline
\end{tabular}

* Foram considerados apenas os itens exigidos pela NBR 9050/2015 e legislação federal em vigor, remetendo-se consulta às leis estaduais e municipais, como complemento, além das recomendações contidas na norma técnica mencionada.

Fonte: Elaborado pelos Autores.

O Quadro 1 mostra, ainda, que as questões referentes à acessibilidade externa estão praticamente resolvidas, necessitando apenas pequenos ajustes como a instalação de corrimão intermediário (ABNT, 2015), única não conformidade encontrada $(11,1 \%)$.

Essas adequações externas são sempre mais exitosas, uma vez que empresas de grande porte e condomínios empresariais habitualmente possuem equipes de manutenção, quando não de engenharia próprias, que em geral resolvem essas questões facilmente dentro do seu próprio cronograma de manutenção.

Observou-se que a rampa de acesso possui inclinação dentro da norma (máximo de $8 \%$ ), sem degraus e desníveis. As aberturas de portas e passagens possuem dimensões de $1,65 \mathrm{~m}$, estando de acordo com a norma (não inferiores a $80 \mathrm{~cm}$ ). Possui banheiro adaptado, para uso exclusivo. Nos banheiros e lavabos, a posição das peças sanitárias, instalação de barras de apoio, além da abertura da porta (para fora), atendem às recomendações da norma técnica brasileira NBR 9050.

O grau de autonomia e independência dentro da UAN, relacionado com o atendimento preferencial, funcionários treinados, intérprete em libras, acesso aos alimentos, utensílios e bebidas e fluxo do salão, também foi avaliado (Quadro 2).

A palavra "autonomia" tem origem grega e refere-se a autos (próprio) e "nomos" (regra, autoridade ou lei) e para a pessoa com deficiência, poderá, portanto, ser interpretada como a "própria regra" ou "própria autoridade" para conduzir sua vida pessoal e social (RIBEIRO, 2006). Desta maneira, o acesso e autonomia da PCD é um processo individual, embora o homem seja um ser de relações que constrói sua identidade por meio das relações que estabelece com o outro e o meio (WINNICOT, 1999).

Na Unidade de Alimentação e Nutrição, observou-se que, as PCD são atendidas à medida que os usuários pedem ajuda e os funcionários apesar de não terem recebido treinamento para acolhimento e atendimento a essas pessoas, são atenciosos e prestativos. No entanto, não se observa promoção da inclusão através da autonomia. É preciso que se faça uma reflexão sobre a questão do auxílio às PCD. 
As empresas por questões legais, dependendo de seu tamanho, devem fazer a inclusão de pessoas com as mais diferentes formas de deficiência. Com isso, preocupam-se quanto à adaptação do ambiente de trabalho e quanto às instalações sanitárias, que também são exigências da lei, porém se esquecem ou talvez não se preocupem com o momento de refeição desse seu colaborador.

O presente estudo observou que, muitas vezes, as Unidades de Alimentação e Nutrição são terceirizadas e não têm funcionários extras ou mesmo capacitados para auxiliar as PCD. Nessa perspectiva, em razão do horário da refeição ser o momento mais atribulado do serviço, portanto deveria caber à empresa empregadora da PCD prover condições suficientes para que esta se sinta amparada em todos os momentos, sem necessidade de ficar pedindo auxílio e gerando desconfortos ou constrangimentos.

Outra questão se trata do planejamento da cozinha, não somente quanto aos espaços, mas também quanto aos equipamentos, que nem sempre possibilitam a autonomia da PCD. Compete à indústria dos equipamentos pensar não somente na eficiência destes, mas que de maneira estes poderão ser projetados para se adequar a legislação da inclusão.

Muitas vezes, os pratos, talheres e bandejas, estão em altura conforme, no entanto, as bebidas e os alimentos não, o que impede que pessoas em cadeira de rodas se sirvam sozinhas e dificulta o acesso aos alimentos (que estão dispostos mais atrás no balcão) às pessoas com nanismo e distrofia.

A altura, a largura do balcão e a não existência do vão encontrados sob os balcões na UAN, são impedimentos para a aproximação frontal, não permitindo que pessoas em cadeiras de rodas consigam se servir, conforme mostra o Quadro 1. Em relação a estes balcões de serviços de atendimento ao público e de distribuição das refeições, estes deveriam dispor de, pelo menos, uma parte da superfície acessível para o atendimento das pessoas com deficiência ou mobilidade reduzida o que não está de acordo com a determinação da lei (ABNT, 2015).

Figura 1 - Medidas Padrão de Balcão de Atendimento
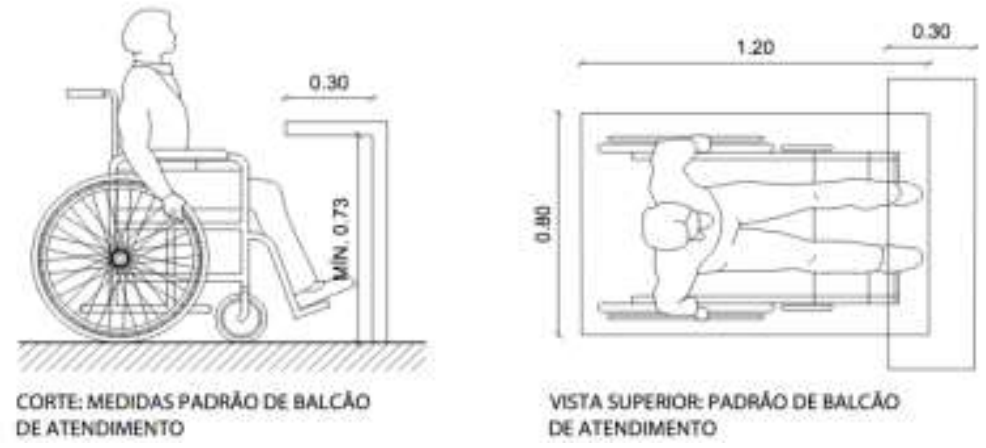

Fonte: Sebrae (2015). Elaborado a partir do desenho de: Juliana Luchsinger Ramos - Arquiteta - CAU $N^{\circ}$ A58257-3.

A circulação dentro do salão é possível ser feita com conforto, os espaços entre as mesas atendem à norma e apesar de algumas mesas serem tipo balcão, há mesas acessíveis e em quantidade suficiente.

A área de café da UAN conta com um espaço amplo de circulação. No entanto, os balcões e máquinas de café se encontram a 1,30 $\mathrm{m}$ acima do piso, o que aliado à falta de um funcionário fixo para atendimento neste local, impossibilita o alcance ao 
cadeirante.

Tendo em vista a parcialidade na promoção ao acesso, é natural que ao observar o comportamento das PCD na UAN sejam notadas diversas situações e o desenrolar dos atendimentos a essas pessoas nem sempre ocorre de maneira satisfatória.

À medida que a deficiência é uma expressão da diversidade humana, apenas se torna uma questão de injustiça quando a estrutura básica da sociedade não consegue tratá-la com equidade, impondo às pessoas com deficiência barreiras físicas ou morais e de dificuldades de acesso aos ambientes sociais (SANTOS, 2008).

Através da observação e contato diário com as PCD, foi possível perceber que há um certo desconforto social em alguns momentos, pois os portadores de necessidades especiais estavam acostumados a se dirigirem a uma única funcionária e ao pedirem ajuda a outra pessoa eles evitavam contato visual, falavam pouco, não questionavam sobre todas as opções. Pessoas com muletas têm dificuldade de, após se servirem, levarem a bandeja até a mesa e após a refeição retorná-la até a devolução. À medida que não há na UAN, funcionário específico para este auxilio, este é solicitado aos colegas e, em último caso, aos estagiários de Nutrição.

Os amputados se servem também com dificuldade, são auxiliados pelos funcionários do balcão de distribuição e precisam solicitar ajuda também para cortar algum alimento e/ou para carregar a bandeja.

Muitas vezes as PCD acabam limitando-se a escolher o alimento mais próximo, o preparo mais fácil ou seguir a sugestão do funcionário que o auxiliou sem muitos questionamentos, o que não ocorre com os outros clientes, demonstrando um certo conformismo quanto às suas possibilidades de acesso.

Em sua pesquisa, Sá (2010), identificou problemas semelhantes, na qual os entrevistados relataram não receber o mesmo tratamento ou as mesmas opções que os demais clientes, sendo comum às pessoas com mobilidade reduzida ficarem restritas a uma área do salão, sentirem falta de auxílio para locomoção e de orientações simples. A retirada de obstáculos do ambiente, indicação de onde ficam talheres, prato, bebidas, ou quais alimentos estão disponíveis no bufê, são relatados como empecilhos mais comuns, além da forma de comunicação, principalmente em relação às pessoas com deficiência auditiva e visual.

Não havia na unidade de alimentação o cardápio em Braille, direito que caminha em tramitação desde o período do presente estudo, que propõe alteração da Lei $n^{\circ}$ 13.146, de 6 de julho de 2015 do Estatuto da Pessoa com Deficiência, pela Lei $n^{\circ}$ 1550, de 2019 que estabelece a obrigatoriedade da disponibilização de cardápio em Braille em restaurantes, bares e lanchonetes (BRASIL, 2019).

Não havia na UAN, intérprete ou funcionário capacitado a comunicar-se pela Língua Brasileira de Sinais, o que pela legislação atual não é uma obrigatoriedade.

O Decreto 5.626, de 2005 em seu Art. 26, prevê a garantia dos serviços de atendimento para surdos em órgãos da administração pública direta, indireta e empresas prestadoras de serviços públicos e instituições financeiras, mas não há nenhuma lei que obrigue bares, restaurantes e serviços de alimentação privados, a prestarem serviços às pessoas surdas. Ou seja, não há uma lei que obrigue os estabelecimentos comerciais a disponibilizar um intérprete de LIBRAS para surdos (BRASIL, 2012).

Foram avaliados neste estudo 25 itens com 56\% (14 itens) de conformidades. No aspecto área física, equipamentos e mobiliário foram avaliados: 18 itens com adequação de apenas $4(22,2 \%)$ na área interna. Dos 7 itens avaliados para identificação dos fatores favoráveis à autonomia das PCD (Quadro 2), 5 (71,4\%) não estavam em conformidade. Maior percentual de conformidade foi para itens 
relacionados às barreiras físicas e estruturais, o que aponta correlação com a literatura, onde estudos, correlacionam a dificuldade a ampliação do conceito de acessibilidade à PCD (BEZERRA, 2007; BARCELLOS; CAMPANTE, 2012). São iniciativas além do cumprimento legislativo, que refletem o interesse pelo cliente e atenção à pluralidade de suas necessidades, promovendo atendimento sem distinções, discriminação ou constrangimentos que muitas vezes passam despercebidos. A empresa inclusiva, que oferece treinamento a seus funcionários a respeito das necessidade e formas de atendimento às PCD, também fortalece a sinergia em torno dos objetivos comuns e reforça o espírito de equipe, valorizando o olhar inclusivo e a perspectiva do coletivo, tornando-se desta maneira, valorizada pelos próprios colaboradores e clientes. Nesse contexto, Shimono (2008) ressalta que as empresas que mudam sua percepção, tornam-se inclusivas, são consideradas competentes e com visão de futuro, agregam valor ao praticarem valores efetivos de responsabilidade social corporativa.

Uma vez que a autonomia da pessoa com deficiência pode ser avaliada pelas atividades da sua vida diária, como lazer, vida social, emocional, independência no trajeto de ir e vir, atividade profissional, entre outras (PEIXOTO; CARVALHO, 2010), é preciso estruturar ações para estimular a autonomia dos indivíduos, para que as diferenças no contexto em que estão inseridas não gerem barreiras que os impeçam de desfrutar de cotidianos sociais, a fim de possibilitar que atuem intencionalmente e com independência, ou seja, com liberdade, no que diz respeito aos atos relacionados à alimentação (OLIVEIRA; OLIVEIRA, 2008; SANTOS; SANTANA; ARRUDA, 2018).

\section{CONCLUSÕES}

A acessibilidade dentro da UAN ainda é pensada como uma tarefa obrigatória e focada nos ajustes físicos da unidade: pensa-se em construir uma rampa, adequar as sinalizações, colocar barras nos banheiros do estabelecimento e realizar adequações que atendam as exigências legais, normas e decretos. No entanto, a acessibilidade deve ir além dos pequenos ajustes, são atitudes que promovem condição de igualdade, fornecendo base para autoconfiança e autonomia, criando uma relação positiva que respeita os pressupostos universais da integridade pessoal. Assim, o nutricionista da Unidade de Alimentação e Nutrição, como profissional da saúde, deve ser responsável não somente pela prevenção e manutenção do estado nutricional dos seus clientes, como, também, garantir que as pessoas com necessidades especiais tenham ampla possibilidade de acesso ao seu serviço e desfrutem dos mesmos direitos dos demais clientes.

Faz-se necessário, ainda, que o nutricionista seja chamado para participar do planejamento das UANs, com os demais membros da equipe (engenheiros, arquitetos, etc), contribuindo com uma visão mais ampla do serviço, além da elaboração de uma planta física.

Neste sentido, conclui-se que adaptações de estrutura externas e de circulação são mais fáceis de serem adaptadas às exigências da legislação, ao contrário de mobiliário e da prestação de serviço, que impacta no número de funcionários da UAN que possam atender os comensais e nas diferentes categorias de necessidades especiais que dificultam, sobremaneira, a possibilidade de oferecer algum grau de autonomia aos seus portadores. A legislação deveria prever que a Empresa fosse responsável por designar um ou mais funcionários, a depender do número de portadores de deficiência, que assumissem a tarefa de auxílio no momento das refeições, uma vez que as UANs, em sua maioria, trabalham com um número bastante 
justo de funcionários, que se encontram em plena atividade nesse horário.

A deficiência em si, é apenas uma característica da diversidade humana e só se torna uma questão de injustiça quando a estrutura básica da sociedade não consegue tratá-la com equidade, agindo de maneira a criar barreiras físicas e morais, que impedem o acesso e autonomia das PCD em ambientes sociais. A relevante incidência de pessoas deficientes na sociedade brasileira por si só já transforma o tema da deficiência em uma questão social, carente de maiores estudos, e de ações no sentido de promover os direitos de cidadania das pessoas que a experimentam, seja por meio das políticas sociais ou outros instrumentos que garantam a justiça.

\section{REFERÊNCIAS}

ABNT NBR9050: 2015. Acessibilidade a edificações, mobiliário, espaços e equipamentos urbanos. Rio de Janeiro: ABNT, 2015. 148 p.

ABREU, E. S.; SPINELLI, M. G. N.; PINTO, A. M. S. Gestão de Unidades de Alimentação e nutrição: um modo de fazer. 7 ed. rev. ampl. São Paulo: Metha; 2019.

ANDRADE, M.S.A ; PACHECO, M. L.; FARIAS, S. S. P. Pessoas com deficiência rumo ao processo de inclusão na educação superior. Rev. Digit. Pesq. CONQUER, Barreiras, v.1, p. 1-5, 2007.

ARAÚJO, C. D. de.; CÂNDIDO, D. R. C.; LEITE, M. F. L. Espaços públicos de lazer: um olhar sobre a acessibilidade para portadores de necessidades especiais. Licere, Belo Horizonte, v. 12, n. 4, dez. 2009. Disponível em:

https://periodicos.ufmg.br/index.php/licere/article/view/835/634. Acesso em: 15 maio 2019.

BAHIA, M. S.; SCHOMMER, P. C. Inserção Profissional de Pessoas com Deficiência em uma Experiência no Brasil e outra em Portugal: Desafios Comuns, Caminhos Diferentes. Pesquisas e Práticas Psicossociais, São João del Rei. v. 6, n.1, p.6277, 2011. Disponível em: https://www.ufsj.edu.br/portal2repositorio/File/revistalapip/volume6 n1/Bahia \%26 Schommer.pdf. Acesso em: 22 maio 2019.

BAHIA, M. S. Responsabilidade social e Diversidade nas Organizações:

Contratando pessoas com deficiência. Rio de Janeiro: Qualitymark, 2006.

BARCELLOS, A. P. de.; CAMPANTE, R. R. A acessibilidade como instrumento de promoção de direitos fundamentais. In: FERRAZ, Carolina Valença. et al. (Coord.). Manual dos direitos da pessoa com deficiência. São Paulo: Ed. Saraiva, 2012.

BEZERRA, R. M. A acessibilidade como condição de cidadania. In: GUGEL, M.A.; MACIEIRA, W.; RIBEIRO, L. (Org.). Deficiência no Brasil: uma abordagem integral dos direitos das pessoas com deficiência. Florianópolis: Ed. Obra Jurídica, 2007.

BRASIL. Cartilha do Censo 2010: Pessoas com Deficiência. Brasília: SDHR/SNPD, 2012. 32p. 
BRASIL. Lei n. 8234, de 17 de setembro de 1991. Regulamenta a profissão de nutricionista e determina outras providências. Brasília, DF: Presidência da República, 1991.

BRASIL. Lei n, 13.146, de 6 de julho de 2015. Institui a Lei Brasileira de Inclusão da Pessoa com Deficiência (Estatuto da Pessoa com Deficiência). Brasília, DF: Presidência da República, 2015. Disponível em: http//www.planalto.gov.br/ccivil _03/_ato2015-2018/2015/lei/113146.htm. Acesso em: 22 maio 2019.

BRASIL. Projeto de Lei $n^{\circ}$ 1550, de 2019. Altera a Lei $n^{\circ} 13.146$, de 6 de julho de 2015 (Estatuto da Pessoa com Deficiência), para estabelecer a obrigatoriedade da disponibilização de cardápio em Braille por bares, lanchonetes e restaurantes.

Brasília, DF: Senado Federal, 2019.

Disponível em: https://www25.senado.leg.br/web/atividade/materias//materia/135798. Acesso em 22 maio 2019.

CARDOSO, V.M.; ARAUJO, J.N.G. Dificultadores e facilitadores no processo de inclusão de pessoas com deficiência no mercado de trabalho. In: SEMINÁRIO INTERNACIONAL; SOCIEDADE INCLUSIVA: PROPOSTAS E AÇOES: IMPASSES E AVANÇOS, 4., 2006, Belo Horizonte. Anais [...]. Minas Gerais: Pontifícia Universidade Católica de Minas Gerais, 2006.

CFN - CONSELHO FEDERAL DE NUTRICIONISTAS. Resolução CFN $\mathbf{n}^{\circ} \mathbf{6 0 0}$, de 25 de fevereiro de 2018. Dispõe sobre a definição das áreas de atuação do nutricionista e suas atribuições, indica parâmetros numéricos mínimos de referência, por área de atuação, para a efetividade dos serviços prestados à sociedade e dá outras providências. Disponível em: https://www.cfn.org.br/wpcontent/uploads/resolucoes/Res 600 2018.htm. Acesso em: 15 maio 2019.

HONNETH, A. Luta por reconhecimento: a gramática moral dos conflitos sociais. Trad. Luiz Repa. São Paulo: editora 34, 2003.

IBGE - INSTITUTO BRASILEIRO DE GEOGRAFIA E ESTATISTICA. Perfil dos estados e dos municípios brasileiros: 2012 / IBGE, Coordenação de População e Indicadores Sociais. - Rio de Janeiro: IBGE, 2013. 226 p.

IBGE - INSTITUTO BRASILEIRO DE GEOGRAFIA E ESTATISTICA. Perfil dos estados e dos municípios brasileiros: 2014 / IBGE, Coordenação de População e Indicadores Sociais. - Rio de Janeiro: IBGE, 2015. 126 p.

IBGE - INSTITUTO BRASILEIRO DE GEOGRAFIA E ESTATISTICA. Perfil dos estados e dos municípios brasileiros: 2018/ IBGE, Coordenação de População e Indicadores Sociais. Rio de Janeiro: IBGE, 2019. 127 p.

LAQUALE, A. A pessoa com deficiência e o direito à acessibilidade. JusBrasil. 2017. Disponível em: https://adonislaquale.jusbrasil.com.br/artigos/469572573/a-pessoacom-deficiencia-e-o-direito-a-acessibilidade. Acesso em: 15 fev. 2020.

NOBRE, A. P. Avaliação da satisfação da clientela em restaurantes do tipo selfservice de Brasília. 2009. Monografia (Especialização em Qualidade dos Alimentos) 
Alimentos, Universidade de Brasilia, Centro de Excelência em Turismo, Brasilia, 2009.

OLIVEIRA, S. I.; OLIVEIRA, K. S. Novas perspectivas em educação alimentar e nutricional. Psicol. USP, São Paulo, v. 19, n. 4, Dec. 2008.

PEIXOTO, J.; CARVALHO R.M. A noção moderna de autonomia e o papel do aluno na educação a distância. Educativa, Goiânia, v.13,n.2, p.252-284, 2010. Disponível em: http://seer.pucgoias.edu.br/index.php/educativa/article/viewFile/1418/934. Acesso em: 23 maio 2019.

PESCHUTI, M. Q.; LIMA, R. C. D. S. A inclusão da pessoa com deficiência no mercado de trabalho. Pedagogia em Foco, Iturama, MG, v. 12, n. 7, p. 102-116, 2017.

RIBEIRO, D.C. Autonomia: viver a própria vida e morrer a própria morte. Cad. Saúde Pública, Rio de Janeiro, v. 22, n. 8, p. 1749-1754, 2006. Disponível em; https://www.scielosp.org/pdf/csp/2006.v22n8/1749-1754 Acesso em: 22 maio 2019.

RIBEIRO, M. A.; CARNEIRO, R. A inclusão indesejada: as empresas brasileiras face à lei de cotas para pessoas com deficiência no mercado de trabalho. Organ. Soc. Salvador, v. 16 , n. 50, p. 545-564, 2009. Disponível em: http://www.scielo.br/scielo.php?script=sci arttext\&pid=S198492302009000300008\&lng=en\&nrm=iso. Acesso em: 20 dez. 2020.

SA, M. Pessoas com Deficiência: um retrato dos problemas que elas enfrentam nos restaurantes. 2010. Trabalho de Conclusão de Curso (Jornalismo), IESB, Brasília, 2010.

SANT'ANA, M. H. P. Planejamento físico funcional de Unidades de Alimentação e Nutrição. Rio de Janeiro: Rubio, 2012.

SANTOS, J. V. M.; SANTANA, A. C.; ARRUDA, G. D. Diversidade nas organizações: inclusão social ou estratégia competitiva? Psicologia.pt., 2018. Disponível em: https://www.psicologia.pt/artigos/textos/A1170.pdf. Acesso em: 03 mar. 2021.

SANTOS, W. R. Pessoas com deficiência: nossa maior minoria. Physis (Rio J.)., v.18, n.3, p.501-519, 2008. Disponível em:

https://www.scielo.br/scielo.php?pid=S0103-

73312008000300008\&script=sci abstract\&tlng=pt. Acesso em: 22 maio 2019.

SÃO PAULO. Secretaria Municipal da Pessoa com Deficiência e Mobilidade Reduzida. SMPED. Manual de instruções técnicas de acessibilidade para apoio ao projeto arquitetônico. São Paulo: Imprensa Oficial do Estado de São Paulo, 2017. 114 p.

SEBRAE. Acessibilidade das empresas de alimentação. Recife, Pe: Sebrae, p. 2015. (Cartilha Sebrae). Disponível em:

https://www.sebrae.com.br/Sebrae/Portal\%20Sebrae/UFs/PE/Anexos/cartilha acessi bilidade alimenta\%C3\%A7\%C3\%A3o.pdf. Acesso em: 22 maio 2019. 
SHIMONO, S.O. Educação e trabalho: caminhos da inclusão na perspectiva da pessoa com deficiência. 2008. Dissertação (Mestrado em Educação) - Faculdade de Educação da Universidade de São Paulo, São Paulo, Brasil, 2008.

SIMONELLI, A. P., JACKSON FILHO, J. M. Análise da inclusão de pessoas com deficiência no trabalho após 25 anos da lei de cotas: uma revisão da literatura. Cad. Bras. Ter. Ocup., São Carlos, v. 25, n. 4, 855-867, 2017. Disponível em: http://www.cadernosdeterapiaocupacional.ufscar.br/index.php/cadernos/article/view/1 842/920. Acesso em: 02 mar. 2020.

TEIXEIRA, S. M. F. G. et al. Administração Aplicada às Unidades de Alimentação e Nutrição. São Paulo: Atheneu, 2010.

TORRES, E.F.; MAZZONI, A.A.; ALVES, J.B.M. A acessibilidade à informação no espaço digital. Ci. Inf., Brasília, v. 31, n. 3, p. 83-91, set./dez. 2002.. Disponível em: https://www.scielo.br/scielo.php?pid=S010019652002000300009\&script=sci abstract\&tlng=pt. Acesso em: 22 maio 2019.

VIANA, C. O. R. et al. Marketing de relacionamento: análise do nível de satisfação do cliente-consumidor da empresa puro sabor. Rev. adm. contab., [s.l.], v. 1, n. 2, 2014. Disponível em: http://revistasfap.com/ojs3/index.php/rac/article/view/134. Acesso em: 22 maio 2019.

WINNICOTT, C. Conversando com os pais. São Paulo: Martins Fontes, 1999.

ZANELLI, J. C. Pesquisa qualitativa em estudos da gestão de pessoas. Estud. psicol., Natal, v. 7, p. 79 - 88, 2002. Disponível em:

https://www.scielo.br/scielo.php?pid=S1413294X2002000300009\&script=sci abstract\&tlng=pt. Acesso em: 17 maio 2019. 